\title{
SEXUAL REPRODUCTION OF KUDZU (PUERARIA MONTANA [LOUR.] MERR.) IN OKLAHOMA
}

\author{
Eric B. Duell \\ Karen R. Hickman \\ Department of Natural Resource Ecology and Management \\ Oklahoma State University \\ Stillwater, OK 74078 \\ eric.duell@okstate.edu
}

Keywords: invasive species, kudzu, sexual reproduction

\begin{abstract}
Non-native invasive plants pose major threats to biodiversity across the globe. In the southeastern United States, kudzu (Pueraria montana [Lour.] Merr.) was introduced as a flowering, ornamental vine. In many areas, it quickly escaped cultivation and has caused major disruption to native ecosystems. Over the past two decades, kudzu has gradually spread north and west, being found as far north as Illinois and Indiana, and as far west as Kansas and Oklahoma. Only recently has the species distribution been thoroughly assessed in Oklahoma, and these studies have found its statewide range to be more extensive than previously thought. As a result of the species being understudied in the region, the reproductive ecology of kudzu in Oklahoma has gone largely unexamined. Our research provides evidence of sexual reproduction at two sites in southeastern Oklahoma. This is the first documentation of germination of kudzu in Oklahoma. While kudzu reproduces primarily through rhizomatous vegetative growth, the production of viable seeds is essential to the maintenance of genetic diversity and is often important at range limits. This research, coupled with further plant demographic research, could provide key details surrounding the potential further spread of kudzu in Oklahoma.

\section{INTRODUCTION}

Invasion by non-native species continues to pose a major threat to native biodiversity and has been identified as a major driver of species extinctions across the globe (Clavero and García-Berthou 2005; Bellard et al. 2016). Non-native invasive plant species pose many threats to native biodiversity, including competition for resource acquisition, alterations in ecosystem functions, and shifting disturbance regimes (Dukes and Mooney 1999; Dillemuth et al. 2008; Corbin and D'Antonio 2010). Invasiveness of introduced plants is often facilitated by a wide variety of physiological and anatomical

characteristics, such as enhanced biomass production, greater root: shoot ratio, or improved seed production (Sandel and Dangremond 2012). According to Forseth and Innis (2004), there are an estimated 6,000 non-native vascular plant species in the U.S., compared to 17,000 native species. Kudzu, Pueraria montana (Lour.) Merr. (Fabaceae), is an introduced, perennial, leguminous vine which can detrimentally alter the ecosystems which it invades. First introduced to the United States as a livestock forage and as an agent for erosion control on degraded landscapes, kudzu has rapidly expanded its range, out-competing native flora and altering biogeochemical processes (Mitich 2000). Due to its vine-
\end{abstract}


forming growth habit and extremely rapid growth rate (Forseth and Innis 2004), kudzu covers and shades out native trees and shrubs, often killing them in the process. Kudzu also has the ability to convert atmospheric nitrogen $\left(\mathrm{N}_{2}\right)$ into plantavailable ammonium $\left(\mathrm{NH}_{4}{ }^{+}\right)$. This pulse of available nitrogen alters the soil chemistry, which can result in the exclusion of plant species better adapted to low-nutrient environments. This, in turn, causes increased rates of nitrogen transformations, namely nitrification and denitrification, and thus increasing emissions of nitrous oxide $\left(\mathrm{N}_{2} \mathrm{O}\right.$ ), a harmful greenhouse gas (Hickman et al. 2010). Along with the impacts on natural ecosystems, kudzu is also economically devastating. An estimated $\$ 100-500$ million is spent annually in an attempt to control kudzu and mitigate the effects of kudzu on forests and agricultural lands (Blaustein 2001).

Once believed to be restricted to parts of the southeastern U.S. because of lack of temperature tolerances, kudzu has spread outside these confines. Kudzu has been documented as far west as Nebraska, Kansas, and Oklahoma, and as far north as New York, Massachusetts, and Ontario (Waldron and Larson 2012), with populations also found throughout the midwestern states of Ohio, Illinois, and Indiana. Some of this is likely due to milder winters experienced by regions at the northern extent of the kudzu range. Climate models predict kudzu could spread even further into northern states such as Michigan and Wisconsin (Jarnevich and Stohlgren 2009; Follak 2011). Other models suggest appropriate climate for kudzu persistence along the west coast from Washington south into California and even Arizona (Bradley et al. 2010; Callen and Miller 2015).

The extent of kudzu invasion in Oklahoma has only been recently assessed. Claytor and Hickman (2015) determined kudzu to be present in 23 of Oklahoma's
77 counties, a more extensive range than previous reports from the state. While the distribution and occurrences of kudzu in Oklahoma have gained recent attention, there are currently no documentations of sexual reproduction of kudzu in the state. Kudzu is a perennial vine, capable of overwintering in a senesced state before emerging in spring via rhizomes. While seed production may not be the primary means of propagation for kudzu, the transport of viable seeds by means of water or wildlife has the potential to further the dispersal of this species, especially in localized populations on the boundaries of its current range. For these reasons, we examined the germinability of seeds collected from kudzu populations identified by Claytor and Hickman (2015).

\section{METHODS}

Legume pods were collected from three Oklahoma sites: Fittstown A, Fittstown B $\left(36^{\circ} 37.48^{\prime} \mathrm{N}, 96^{\circ} 38.6^{\prime} \mathrm{W}\right)$, and Claremore $\left(36^{\circ} 17.56^{\prime} \mathrm{N}, 95^{\circ} 35.56^{\prime} \mathrm{W}\right)$, which were identified by Claytor and Hickman (2015) (Figure 1). Individual seeds were then extracted from legumes. Seeds were surfacesterilized by soaking in 7\% sodium hypochlorite solution for five minutes and thoroughly rinsed using distilled water (Ruiz et al. 2003). Once sterilized and rinsed, seeds were then scarified using sandpaper. Once sterilized, rinsed, and scarified, 50 seeds from each site were placed on top of germination paper fitted in the bottom of a standard (90 mm x $15 \mathrm{~mm}$ ) petri dish. Each site was replicated six times, giving us a total of 18 petri dishes. Germination experiments were conducted in Controlled Environmental Chambers (Conviron-PGW 36, interior dimension: 98 " W x 54" D x 93 " $\mathrm{H}$, growth area: $36 \mathrm{ft}^{2}$, and growth capacity: $240 \mathrm{ft}^{2}$ ) under a 14-hour photoperiod, located on the campus of Oklahoma State University in Stillwater, OK, USA. Ambient temperatures were 
maintained at $24^{\circ} \mathrm{C}$. Germination was considered successful once the radicle had reached approximately $2 \mathrm{~mm}$ in length. To avoid counting previously recorded germinations, germinated seeds were discarded following initial documentation.

Due to the non-normal distribution of our data, a Kruskal-Wallis test was performed with site as the sole factor to determine differences in germination among the three sites. To determine differences among sites, a Dunn's post-hoc test was used $(\alpha=0.05)$. All data were analyzed using R Version 3.6.1 (R Core Team 2019).

\section{RESULTS}

In our study, 86 of 900 seeds germinated. All 86 germinated seeds were collected from Fittstown, with no germination occurring in seeds collected from Claremore (Figure 2). Nearly 10\% of seeds from Fittstown A germinated while germination occurred in 19\% of seeds collected from Fittstown B (see Figure 2).

Germination of seeds from both Fittstown sites was significantly greater than that of Claremore ( $p=0.008 ; \mathrm{p}=0.012)$, and there was no difference in germination between the two Fittstown sites $(p=0.522)$. From these data, we can conclude that, given appropriate conditions, kudzu is capable of sexual reproduction in Oklahoma.

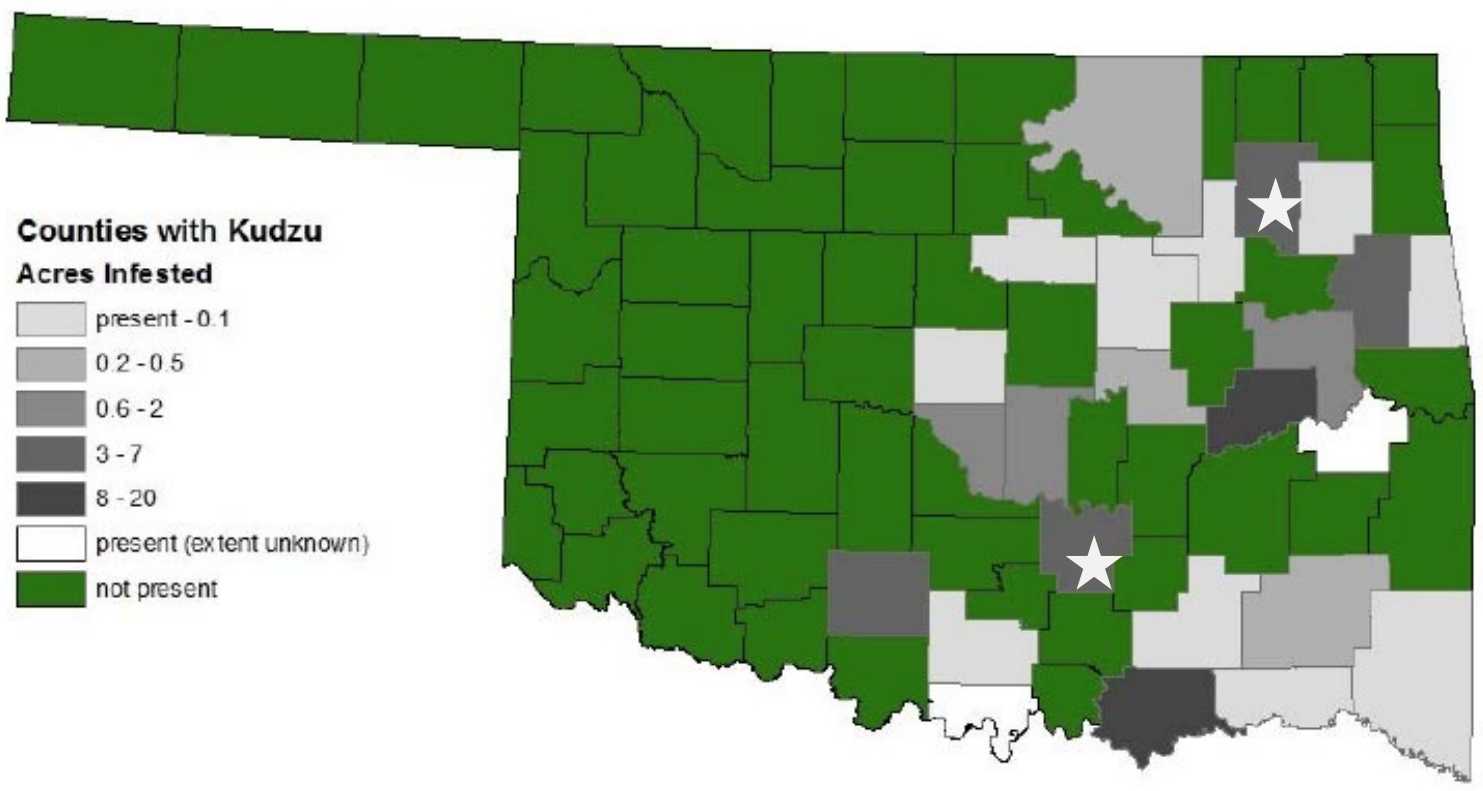

Figure 1 Map of kudzu populations in Oklahoma. Stars indicate the locations of seeds collected for the germination experiment, with Fittstown located in south-central Oklahoma and Claremore being the northeastern site. Map created by Claytor and Hickman 2015. 


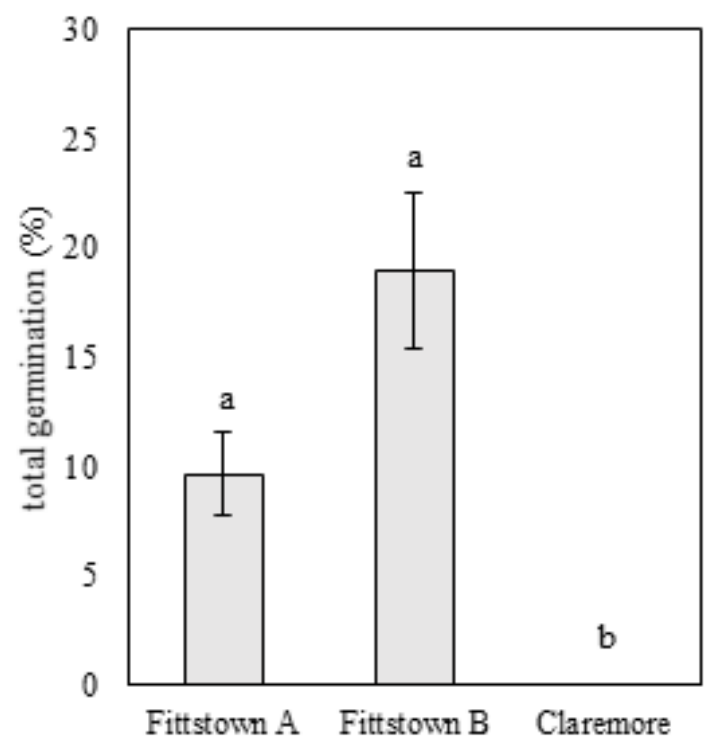

Figure 2 Germination of kudzu from three sites in eastern Oklahoma. Different letters indicate significant differences in germination between sites ( $p \leq 0.05)$.

\section{DISCUSSION AND CONCLUSIONS}

Current and predictive climate models suggest Oklahoma's climate is suitable for sustaining kudzu populations in many parts of the state (Bradley et al. 2010; Callen and Miller 2015). Until now, documentation of viable kudzu seed in Oklahoma has gone unreported. Along with the data collected by Claytor and Hickman (2015), our research suggests that not only is kudzu able to overwinter in parts of the state, but it is also capable of sexual reproduction given appropriate environmental conditions.

While it has been documented that vegetative (asexual) reproduction is the primary mode of propagation in kudzu (Forseth and Innis 2004; Lindgren et al. 2013), sexual reproduction and dispersal is often important for genetic diversity and long-term population persistence in plants. In our study, only seeds collected from Fittstown successfully germinated, while no germination was observed in seeds from Claremore. These results are supported by previous research that suggests kudzu produces relatively few viable seeds, and in some instances populations fail to produce viable seed altogether (Tsugawa 1986a, b). Our results are also supported by McClain et al. (2006), who found that 72 of 78 studied kudzu populations did not produce mature fruit at northern edges of its range. Fruit maturation and subsequent viable seed production are thought to be linked to microclimate (Pappert et al. 2000), which could be one reason why Claremore seeds did not germinate. Average annual temperatures near Fittstown are between 1.5 and $2^{\circ} \mathrm{C}$ warmer than Claremore, and it is possible that this difference is enough to influence germinability. Germination of seeds from Fittstown was found to be similar to seeds from other areas of the southeastern United States (10-20\%), and it is suggested that germination of just a few individuals is adequate for the introduction of new genotypes and addition of genetic diversity to populations (Pappert et al. 2000).

Our study assessed three populations of kudzu for seed germinability. To fill knowledge gaps in the reproductive ecology of kudzu in Oklahoma, additional research is needed to further determine which populations are capable of sexual reproduction. Furthermore, much research is needed regarding the population demographics and genetic diversity of kudzu at the western extent of its invaded range. This will help determine the relative importance of different reproductive strategies (asexual vs. sexual), as well as potential modes of dispersal. This type of research will also aid in early detection and rapid response and potentially slow or halt the spread of this invasive species. 


\section{ACKNOWLEDGMENTS}

We would like to thank J. Nolan Craun and Callie Zoeller for the collection of seeds and assistance with germination trials. Thanks to the Oklahoma Agricultural Experiment Station for additional funding and support.

\section{LITERATURE CITED}

Bellard, C., P. Cassey, and T.M. Blackburn. 2016. Alien species as a driver of recent extinctions. Biology Letters 12:20150623. http://doi.org/10.1098/rsbl.2015.0623

Blaustein, R.J. 2001. Kudzu's invasion into the Southern United States life and culture. In: McNeeley, J.A., ed. The Great Reshuffling: Human Dimensions of Invasive Species. Gland, (Switzerland) and Cambridge (UK): IUCN, The World Conservation Union. pp. 55-62.

Bradley, B.A., D.S. Wilcove, and M. Oppenheimer. 2010. Climate change increases risk of plant invasion in the eastern United States. Biological Invasions 12:1855-1872.

Callen, S.T. and A.J. Miller. 2015. Signatures of niche conservatism and niche shift in the North American kudzu (Pueraria montana) invasion. Diversity and Distributions 21:853-863.

Clavero, M. and E. García-Berthou. 2005. Invasive species are a leading cause of animal extinctions. Trends in Ecology and Evolution 20:110.

Claytor, M. and K.R. Hickman. 2015. Kudzu, Pueraria montana (Lour.) Merr. abundance and distribution in Oklahoma. Oklahoma Native Plant Record 15(1):96-104.

Corbin, J.D. and C.M. D'Antonio. 2010. Not novel, just better: Competition between native and non-native plants in California grasslands that share species traits. Plant Ecology 209:71-81.

Dillemuth, F.P., E.A. Rietschier, and J.T. Cronin. 2008. Patch dynamics of a native grass in relation to the spread of invasive smooth brome (Bromus inermis). Biological Invasions 11:1381-1391.

Dukes, J.S. and H.A. Mooney. 1999. Does global change increase the success of biological invaders? Trends in Ecology and Evolution 14:135-139.

Follak, S. 2011. Potential distribution and environmental threat of Pueraria lobata. Central European Journal of Biology 6(3):457-469.

Forseth, I.N. and A.N. Innis. 2004. Kudzu (Pueraria montana): History, physiology, and ecology combine to make a major ecosystem threat. Critical Reviews in Plant Sciences 23:401-413.

Hickman, J.E., S. Wu, L.J. Mickley, M.T. Lerdau, and C.B. Field. 2010. Kudzu (Pueraria montana) invasion doubles emissions of nitric oxide and increases ozone pollution. Proceedings of the National Academy of Sciences 107(22):10115-10119.

Jarnevich, C. and T. Stohlgren. 2009. Near term climate projections for invasive species distributions. Biological Invasions 11:1373-1379.

Lindgren, C.J., K.L. Castro, H.A. Coiner, R.E. Nurse, and S.J. Darbyshire. 2013. The biology of invasive alien plants in Canada. 12. Pueraria montana var. lobata (Willd.) Sanjappa and Predeep. Canadian Journal of Plant Science 93(1):71-95.

McClain, W.E., J. Shimp, T.L. Esker, J.M. Coons, E.T. Adler, and J.E. Ebinger. 2006. Distribution and reproductive potential of kudzu (Pueraria lobata, Fabaceae) in Illinois, USA. Transactions of the Illinois State Academy of Science 99(12):17-30.

Mitich, L.W. 2000. Kudzu (Pueraria lobata [Willd.] Ohwi.). Weed Technology 14:231235.

Pappert, R.A., J.L. Hamrick, and L.A. Donovan. 2000. Genetic variation in Pueraria lobata (Fabaceae), an introduced, clonal, invasive plant of the southeastern United States. American Journal of Botany 87:1240-1245. 
R Core Team. 2018. R: A language and environment for statistical computing. Vienna (Austria): R Foundation for Statistical Computing. https://www.Rproject.org/

Ruiz, O.N., H.S. Hussein, N. Terry, and H. Daniell. 2003. Phytoremediation of organomercurial compounds via chloroplast genetic engineering. Plant Physiology 132:1344-1352.

Sandel, B. and E.M. Dangremond. 2012. Climate change and the invasion of California by grasses. Global Change Biology 18:277-289.
Tsugawa, H. 1986a. Cultivation and utilization of kudzu-vine (Pueraria lobata Ohwi). Taxonomy, geographical distribution, use, breeding, and propagation. Journal of Japanese Society of Grassland Science 31:435-443.

Tsugawa, H. 1986b. Cultivation and utilization of kudzu-vine (Pueraria lobata Ohwi). Adaptability, cultivation method, cutting frequency, yield, grazing, and feeding value. Journal of Japanese Society of Grassland Science 32:173-183.

Waldron, G.E. and B.M. Larson. 2012. Kudzu vine, Pueraria montana, adventive in southern Ontario. The Canadian FieldNaturalist 126(1):31-33. 